\title{
Development and Validation of a Single HPLC Method for Analysis of Purines in Fish Oil Supplements
}

\author{
Liton Roy, Chad C. Harrell, Alan S. Ryan, Thorsteinn Thorsteinsson, Frederick D. Sancilio
}

Department of R \& D, Sancilio and Company, Inc., Riviera Beach, USA.

Email: alryan@sancilio.com

Received September $24^{\text {th }}, 2013$; revised October $24^{\text {th }}, 2013$; accepted November $2^{\text {nd }}, 2013$

Copyright (C) 2013 Liton Roy et al. This is an open access article distributed under the Creative Commons Attribution License, which permits unrestricted use, distribution, and reproduction in any medium, provided the original work is properly cited. In accordance of the Creative Commons Attribution License all Copyrights (C) 2013 are reserved for SCIRP and the owner of the intellectual property Liton Roy et al. All Copyright (C) 2013 are guarded by law and by SCIRP as a guardian.

\begin{abstract}
Gout is one of the most common forms of inflammatory arthritis, affecting over 8 million adults in the US. Individuals with gout are advised to avoid the habitual intake of purine-rich foods such as meats, seafood, purine-rich vegetables, and animal protein. An increased risk of developing or having subsequent attacks of gout is particularly associated with the consumption of seafood. However, clinical studies have shown that certain seafood and fish oil supplements that contain large amounts of omega-3 fatty acids provide important cardiovascular benefits. Individuals who might benefit from omega-3 fatty acid supplementation may therefore avoid fish oil products because they contain purines. Currently, there are no distinct high-performance liquid chromatography (HPLC) methods available in the literature that are validated as per the International Conference on Harmonisation (ICH) guidelines for the analysis of omega-3 fatty acid oils or fish oil containing products for purine content. A robust, fast, and efficient reversed-phase high-performance liquid chromatography (RP-HPLC) method was developed and validated for the specific analysis of the naturally occurring purines guanine, purine, theobromine, and adenine. These purines are often found in fish oil and seafood. The analytical method reported herein quantifies all four purines in fish oil in about 20 minutes.
\end{abstract}

Keywords: Purines; Chromatography; Gout; Uric Acid; Omega-3 Fatty Acids

\section{Introduction}

Gout is a type of inflammatory arthritis that is associated with the accumulation of uric acid, also known as hyperuricemia [1]. If too much uric acid accumulates in the blood, crystals (monosodium urate) are formed, and the crystals deposit in joints, tendons, and surrounding tissues. These crystals cause joints to swell and become inflamed [1]. Gout leads to substantial morbidity and severe pain [1]. The prevalence of gout in the US has more than doubled between the 1960s and the 1990s [2]. Based on data from the latest nationally representative sample of US adults (National Health and Nutrition Examination Survey, [NHANES, 2007-2008]) the prevalence of gout was $3.9 \%$ (8.3 million individuals) in 2007-2008 [1]. A western diet, sedentary lifestyle, increased prevalence of obesity and hypertension, and increased use of diuretics and aspirin have been linked to the growing prevalence of gout [3]. In particular, the dietary intake of purine-rich foods such as red meats, anchovies, sardines, beans, peas, lentils, and spinach is associated with hyperuricemia because the human body produces uric acid when it breaks down purines [4]. The risk of gout associated with seafood consumption is particularly high, especially among men [5]. As a result, individuals who are susceptible to gout are often careful to avoid dietary products that contain large amounts of purines.

The long-chain polyunsaturated omega- 3 fatty acids eicosapentaenoic acid (EPA) and docosahexaenoic acid (DHA) are found mainly in marine foods, particularly in cold water fish like salmon, anchovies, sardines, and herring. Some of these fish are also known to contain large amounts of purines. However, many clinical studies have demonstrated that EPA and DHA provide numerous cardiovascular benefits [6]. Both EPA and DHA reduce serum triglyceride and very low-density lipoprotein cholesterol (VLDL-C) levels by $30 \%$ or more. Both DHA and EPA have also been shown to modestly raise high-density lipoprotein cholesterol (HDL-C) and lower total choles- 
terol, especially in individuals with high triglyceride levels who are taking statins [6]. As a result, numerous dietary supplements available in the marketplace, including cod liver oil, contain fish oil with the omega-3 fatty acids EPA and DHA. Additionally, the Food and Drug Administration (FDA) has recently approved two drugs (Lovaza $^{\circledR}$ and Vascepa ${ }^{\circledR}$ ) that contain concentrated levels of omega-3 fatty acids from fish oil. These drugs are indicated for individuals with severe hypertriglyceridemia or elevated triglyceride levels $(>500 \mathrm{mg} / \mathrm{dL})$.

Purines in fish oil used for drugs and some dietary omega-3 fatty acid supplements are typically eliminated during the purification and distillation process. However, not all dietary omega-3 fatty acids supplements have been evaluated for purine content; some may contain indeterminate levels of purine. Other commercially available products such as sardines and cod liver oil also have not been evaluated for purine content. The primary objective of the present study is to describe a new reversed-phase high-performance liquid chromatography (RP-HPLC) method that allows the testing of purine levels in omega-3 fatty acid fish oils and other fish products.

\section{Experimental Methods}

\subsection{Chemical and Reagents}

Guanine, purine, theobromine, and adenine were purchased from Acros Organics, NJ (Purity: 99.9\%). HPLC grade solvents used for the sample preparations and chromatography analyses were obtained from Fisher Scientific, Pittsburgh, PA. Pharmaceutical grade, super concentrated omega-3 fatty acid fish oil samples (Ocean Blue ${ }^{\circledR}$ Professional Omega-3 $2100^{\mathrm{TM}}$ ) were obtained from Sancilio and Company, Inc., Riviera Beach, FL. Commercially available fish oil from sardines and cod liver oil (Nature's Way) were obtained from the local supermarket (West Palm Beach, FL).

\subsection{Instrumentation}

The Agilent 1100 series HPLC system equipped with multiple wavelength detector, on-line degasser, and column compartment with temperature control was used for method development and validation. Data acquisition, analysis, and reporting were performed using ChemStation (Agilent) software. The HPLC columns $(250 \times 4.6$ $\mathrm{mm}$ ID) and Luna 5u Silica 100A were purchased from Phenomenex, Torrance, CA. The ODS Hypersil 5u 120A was obtained from Thermo Scientific, Waltham, MA. The detection wavelength of $270 \mathrm{~nm}$ and sample injection of $10 \mu \mathrm{L}$ with an auto sampler was used.

\subsection{Sample Preparation}

Purine stock solution was prepared by transferring $5 \mathrm{mg}$ of each purine standard into a $50 \mathrm{~mL}$ volumetric flask.
The solution was diluted to volume with diluent (80:20 methanol: water) to achieve a stock concentration of 100 $\mu \mathrm{g} / \mathrm{mL}$. For method validation experiments, stock purine solution was diluted with diluent to achieve the desired concentration levels relative to the analytical concentration $(1 \mu \mathrm{g} / \mathrm{mL}$ is also referred as $100 \%$ level). All samples and mobile phase were stored at ambient temperature.

Omega-3 fatty acid oil samples were prepared by transferring $100 \mathrm{mg}$ of the oil into a $50 \mathrm{~mL}$ volumetric flask and then diluted with $95 \%$ methanol. Volume was adjusted with water. The mixture was sonicated for 1 hour to obtain a homogenous mixture.

\subsection{Method Development}

High aqueous RC-HPLC with end capped reverse phase columns was utilized to retain and separate polar compounds. Absorbance of the eluent was measured at 270 $\mathrm{nm}$. Different mobile phase gradients of water and methanol were used during method development to obtain separation between purines. Initial experiments were conducted on the ODS Hypersil C18 $250 \times 4.6 \mathrm{~mm}$ column. However, the Phenomenex Luna C18 $250 \times 4.6$ $\mathrm{mm}$ produced the desired separation with tailing factors less than 2.0 for all purines and resolution of more than 2.0 between peaks at concentration levels ranging from $0.05 \mu \mathrm{g} / \mathrm{mL}$ to $100 \mu \mathrm{g} / \mathrm{mL}$.

\subsection{Method Validation Studies}

The chromatographic method was validated for sensitivity, linearity, range, accuracy, precision, specificity, and robustness. The sensitivity of the method was determined by establishing the limit of detection (LOD) and limit of quantitation (LOQ) for each purine with signal-to-noiseratios of $3: 1$ and 10:1, respectively.

\section{Results}

The resolutions and tailing factors for the 4 purines are shown in Table 1. The resolutions are all greater than 2, whereas the tailing factors are not more than 2 , which are in accordance with United States Pharmacopeia (USP) criteria. Chromatographic conditions are summarized in Table 2. The injection volume of $10 \mu \mathrm{L}$ represents an acceptable level of reproducibility while extending the longevity of the column. The mobile phases of water and methanol facilitate use of the HPLC.

Figure 1 shows the representative chromatograms for each purine: guanine, purine, theobromine, and adenine at $10 \mu \mathrm{g} / \mathrm{mL}$ concentration, respectively. Since the method was conducted at $270 \mathrm{~nm}$, the peaks of the chromatograms for each purine are easy to distinguish.

According to Figure 2(a), the omega-3 fatty acid fish oil sample obtained from Sancilio and Company, Inc. 
Table 1. Resolutions (R) and USP tailing factors (TF) for the four purines evaluated.

\begin{tabular}{ccccccccc}
\hline \multirow{2}{*}{$\begin{array}{c}\text { Concentration } \\
(\mu \mathrm{g} / \mathrm{mL})\end{array}$} & \multicolumn{2}{c}{ Guanine } & \multicolumn{2}{c}{ Purine } & \multicolumn{2}{c}{ Theobromine } & \multicolumn{2}{c}{ Adenine } \\
\cline { 2 - 9 } & $\mathrm{R}$ & $\mathrm{TF}$ & $\mathrm{R}$ & $\mathrm{TF}$ & $\mathrm{R}$ & $\mathrm{TF}$ & $\mathrm{R}$ & $\mathrm{TF}$ \\
\hline 0.05 & - & 1.1 & 6.9 & 1.5 & 3.9 & 1.2 & 4.4 & 1.1 \\
1 & - & 1.1 & 7.0 & 1.4 & 3.9 & 1.3 & 3.9 & 1.4 \\
40 & - & 1.1 & 6.6 & 1.5 & 3.7 & 1.5 & 4.0 & 1.7 \\
100 & - & 1.1 & 4.6 & 1.6 & 3.4 & 1.8 & 3.2 & 2.0 \\
\hline
\end{tabular}

Table 2. Chromatographic conditions.

\begin{tabular}{cc}
\hline Time (minutes) & $\%$ MPB \\
\hline 0.0 & 1 \\
3.0 & 1 \\
10.0 & 35 \\
10.10 & 85 \\
13.0 & 85 \\
13.1 & 1 \\
20.0 & 1
\end{tabular}

Equipment: HPLC system with degasser, autosampler, and MWD detector. HPLC column: Phenomenex Luna Silica analytical column $250 \times 4.6 \mathrm{~mm} 5$ micron. Flow rate: $1.0 \mathrm{~mL} / \mathrm{min}$. Injection volume: $10 \mu \mathrm{L}$. Wavelength: 270 $\mathrm{nm}, 16 \mathrm{BW}$, Reference $360 \mathrm{~nm}$. Mobile phase A: 100\% Water. Mobile phase B: 100\% Methanol. Column temperature: Ambient. Run time: 20 minutes.

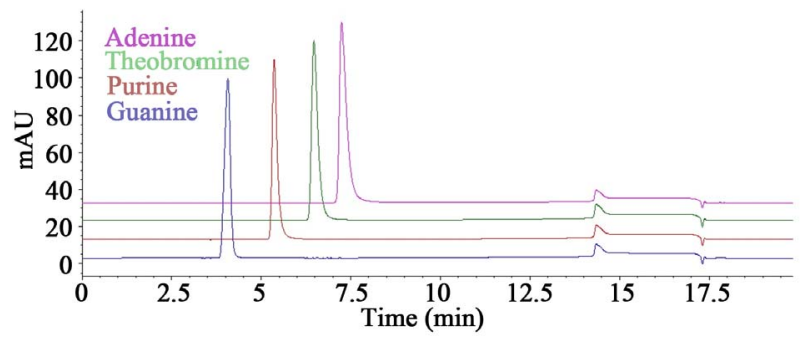

Figure 1. HPLC chromatogram overlay of guanine, purine, theobromine, and adenine.

was free of purines. Fish oil obtained from sardines (Figure 2(b)) contained $0.8 \mathrm{mg} / \mathrm{g}$ of guanine and $2.9 \mathrm{mg} / \mathrm{g}$ of purine. Cod liver oil (Figure 2(c)) contained $4.1 \mathrm{mg} / \mathrm{g}$ of guanine and $1.7 \mathrm{mg} / \mathrm{g}$ of purine.

\subsection{Linearity and Range}

Linearity of the assay was demonstrated by analyzing the peak responses against the analytical concentrations at various concentrations. The method was linear between the concentration ranges of $0.05 \mu \mathrm{g} / \mathrm{mL}$ to $1.00 \mu \mathrm{g} / \mathrm{mL}$ for all 4 purines, with the linear correlation coefficient $\geq$

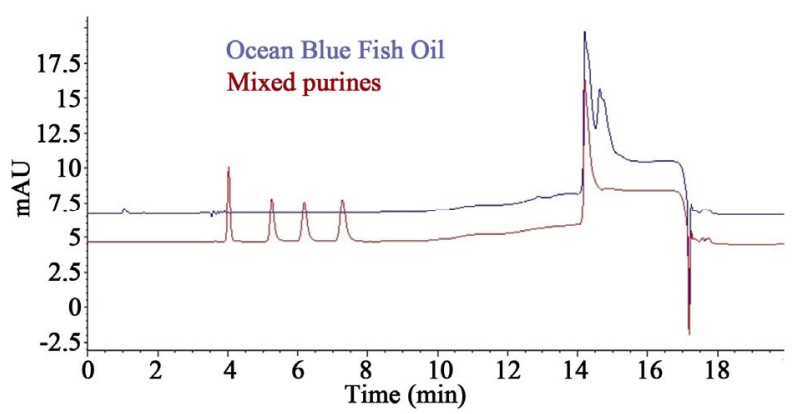

(a)

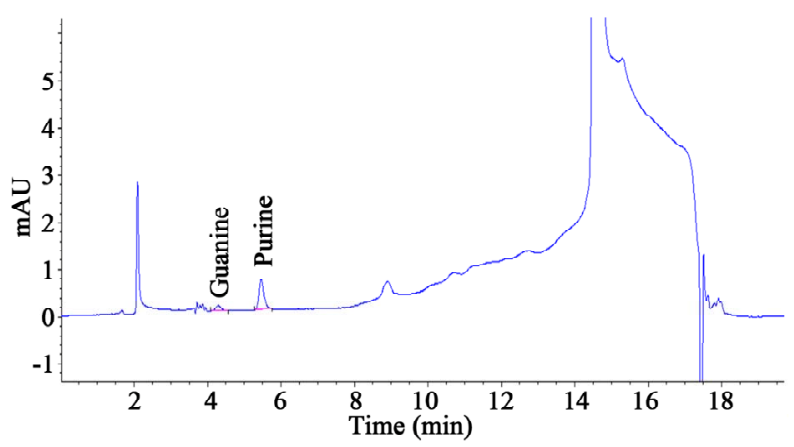

(b)

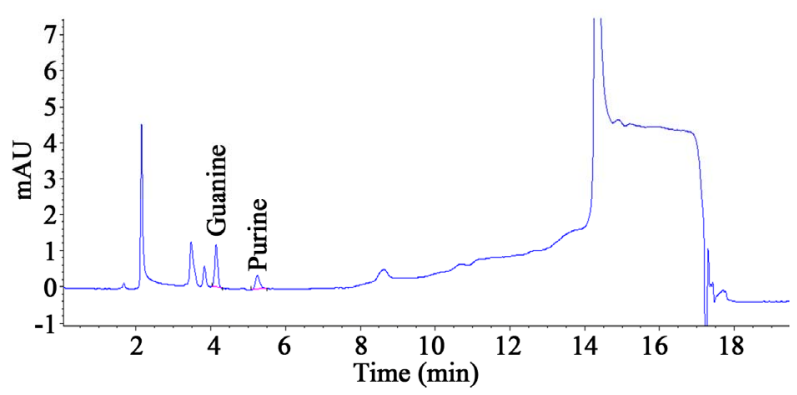

(c)

Figure 2. (a) HPLC overlay of purine standards and omega3 fatty acid fish oil; (b) HPLC chromatogram of fish oil obtained from sardines. Fish oil from sardines contained 0.8 $\mathrm{mg} / \mathrm{g}$ of guanine and $2.9 \mathrm{mg} / \mathrm{g}$ of purine; (c) HPLC chromatogram of fish oil obtained from cod liver. Fish oil from cod liver contained $4.1 \mathrm{mg} / \mathrm{g}$ of guanine and $1.7 \mathrm{mg} / \mathrm{g}$ of purine.

0.9999. For all 4 purines, the limit of quantification (LOQ) ranged from 0.02 to $0.04 \mu \mathrm{g} / \mathrm{mL}$ and the limit of detection (LOD) was determined to be $0.01 \mu \mathrm{g} / \mathrm{mL}$. For quantifying the contents of purines in the fish oil samples, the established sensitivity appeared to be sufficient.

\subsection{Accuracy and Precision}

The accuracy and precision of the method were verified by evaluating percent recovery of purines from spiked omega-3 fatty acid fish oil samples (Table 3). The omega-3 fatty acid fish oil samples were spiked with all four purines at $2 \mu \mathrm{g} / \mathrm{mL}, 10 \mu \mathrm{g} / \mathrm{mL}$, and $20 \mu \mathrm{g} / \mathrm{mL}$ concentration levels. The assay recovery values were ana- 
Table 3. Accuracy and precision of HPLC method.

\begin{tabular}{ccccccc}
\hline & $2 \mu \mathrm{g} / \mathrm{mL}$ level & \multicolumn{2}{c}{$10 \mu \mathrm{g} / \mathrm{mL}$ level } & \multicolumn{2}{c}{$20 \mu \mathrm{g} / \mathrm{mL}$ level } \\
\hline & $\%$ & $\%$ & $\%$ & $\%$ & $\%$ & $\%$ \\
Recovery & $R S D$ & Recovery & $R S D$ & Recovery & $R S D$ \\
\hline Guanine & 104 & 1.7 & 103 & 0.5 & 102 & 0.4 \\
Purine & 101 & 3.1 & 100 & 0.0 & 100 & 0.1 \\
Theobromine & 99 & 2.2 & 101 & 0.1 & 100 & 0.1 \\
Adenine & 100 & 2.0 & 102 & 0.1 & 102 & 1.7 \\
\hline
\end{tabular}

lyzed for the individual preparations against purine standards solutions. The average (mean) percent recovery was between $99 \%$ and $104 \%$, indicating excellent accuracy. The percent standard deviations (\% RSD) of three replicate preparations were between 0.1 and 3.1, showing good precision of the method used.

\subsection{Robustness}

Small and deliberate variations in HPLC parameters were made to verify the robustness of the analytical method. The HPLC parameter variations studied included flow rate $(1.0 \pm 0.1 \mathrm{~mL} / \mathrm{min})$, column temperature $\left(25^{\circ} \mathrm{C} \pm\right.$ $\left.3^{\circ} \mathrm{C}\right)$, wavelength $(270 \pm 2 \mathrm{~nm})$, injection volume $(10 \pm 5$ $\mu \mathrm{L}$ ), and a different lot of column (Table 2). For all the HPLC variations, the chromatography was comparable to the procedural conditions in terms of peak resolution, peak tailing, and injection precision. The method was, therefore, considered to be robust.

\subsection{Specificity}

Method specificity was established by demonstrating that there was no interfering peak from the diluent or omega3 fatty acid fish oil free of purines. Peak homogeneity of the purine samples were evaluated using a HPLC with a photodiode array detector. No degradation was observed for the purine standards in solution stored at ambient conditions and exposed to light for up to 15 days. Figure 2(a) is a representative chromatogram of the omega-3 fatty acid fish oil sample and the four purine standards.

\section{Discussion}

Gout management requires a comprehensive strategy that considers the underlying causes of hyperuricemia [4]. Successful uric-acid lowering will prevent frequent goat attacks and disease progression. Uric acid-lowering drugs are usually prescribed concomitant with nonsteroidal anti-inflammatory agents (NSAIDs) to reduce inflammation and pain [4]. For proper gout management, a dietary change involving the reduced intake of purine-rich foods is a prudent approach accompanied by regular monitoring of serum uric acid levels. For those with gout, it is important to follow a strict, low-purine diet. Knowing the amount of purines in different food products may help reduce the risk of gout flare-ups induced by abrupt changes in serum uric acid levels.

This paper describes a simple, efficient, and reproducible RP-HPLC method specifically for the analysis of naturally occurring purines in fish oils and other food products. The resulting method has been fully validated as per ICH guidelines [7]. As the new method is a simple and reproducible approach, it can be easily implemented in a quality controlled laboratory. To the best of our knowledge, this is the first fully ICH validated RP-HPLC method that can be used as a single procedure to quantify accurately the amount of guanine, purine, theobromine, and adenine in fish oils in about 20 minutes. Three commercially available fish oil products were analyzed: a super concentrated omega-3 fatty acid fish oil sample (Ocean Blue ${ }^{\circledR}$ Professional Omega-3 2100 ${ }^{\mathrm{TM}}$ ) and fish oil from sardines and cod liver oil. While the Ocean Blue ${ }^{\circledR}$ omega-3 fatty acid fish oil sample was free of purines, the fish oil from sardines and cod liver oil contained substantial amounts of guanine and purine. Notably, this method can also be used to quantify the amount of purines in various other matrices provided that the purine peaks do not interfere with the matrix.

The ability to retain and separate polar and hydrophilic molecules such as purines was very challenging. When using conventional reverse phase liquid chromatography, it is necessary to use ion pair reagents, mobile phase $\mathrm{pH}$ modification, and concentrated buffers [8]. Such an approach may have potential detrimental effects on method reproducibility and sample solubility. Using conventional techniques also result in poor retentions and separations. An optimized gradient chromatography system allows the detection of guanine, purine, theobromine, and adenine at very low concentrations [9]. As described in this paper, chromatographic peaks were identified via the retention times of known standards, with detection at 270 $\mathrm{nm}$ wavelength [10]. The Liquid Chromatography Mass Spectrometry (LC-MS) compatible mobile phase of the new method is useful in the identification of any future potentially unknown and or new chromatographic peaks that may be present in commercially available fish oil samples.

\section{Conclusion}

In sum, a simple, efficient, reproducible RP-HPLC method has been developed for the analysis of naturally occurring purines in fish oils. An LC-MS compatible mobile phase would allow the analysis of any contaminates found in fish oils. Such applications are currently underway in our research and development laboratory at Sancilio and Company, Inc. 


\section{Acknowledgements}

The authors thank our colleagues in the Analytical Research and Development Department at Sancilio and Company Inc. for their support during this study.

\section{REFERENCES}

[1] Y. Zhu, B. J. Pandya and H. K. Choi, "Prevalence of Gout and Hyperuricemia in the US General Population, the National Health and Nutrition Examination Survey 2007-2008," Arthritis \& Rheumatism, Vol. 63, No. 10, 2011, pp. 3136-3141. http://dx.doi.org/10.1002/art.30520

[2] R. C. Lawrence, D. T. Felson, C. G. Helmick, L. M. Arnold, H. Choi, R. A. Deyo, et al. (For the National Arthritis Data Workgroup), "Estimates of the Prevalence of Arthritis and Other Rheumatic Conditions in the United States, Part II," Arthritis \& Rheumatism, Vol. 58, No. 1, 2008, pp. 26-35. http://dx.doi.org/10.1002/art.23176

[3] J. D. Bieber, R. S. Terkeltaub, "Gout: On the Brink of Novel Therapeutic Options for an Ancient Disease," Arthritis \& Rheumatism, Vol. 50, No. 8, 2004, pp. 24002414. http://dx.doi.org/10.1002/art.20438

[4] H. R. Schumacher Jr. and L. X. Chen, "The Practical Management of Gout," Cleveland Clinic Journal of Medicine, Vol. 75, Suppl. 5, 2008, pp. S22-S25. http://dx.doi.org/10.3949/ccjm.75.Suppl 5.S22

[5] H. K. Choi, K. Atkinson, E. W. Karlson, W. Willett and G. Curhan, "Purine-Rich Foods, Dairy and Protein Intake, and the Risk of Gout in Men," New England Journal of Medicine Vol. 350, No. 11, 2004, pp. 1093-1103. http://dx.doi.org/10.1056/NEJMoa035700

[6] A. S. Ryan and F. D. Sancilio, "Prevention of Cardiovascular Disease with Omega-3 Polyunsaturated Fatty Acids," Journal of Clinical Studies, Vol. 4, No. 6, 2012, pp. 30-33.

[7] International Conference on Harmonisation Tripartite Guideline, "Validation of Analytical Procedures: Text and Methodology," ICH Secretariat, Geneva, 2005.

[8] L. A. Rogers, K. E. Crews, S. G. Long, K. M. Patterson and J. E. McCune, "Evaluation of Chromatographic Methods for Drug Products Containing Polar and Non-Polar Molecules Using Reversed Phase, Hydrophilic Interaction, and Ion Exchange Chromatography," Journal of Liquid Chromatography \& Related Technologies, Vol. 32, No. 15, 2009, pp. 2246-2264. http://dx.doi.org/10.1080/10826070903163057

[9] N. Yamaoka, K. Kaneko, Y. Kudo, M. Aoki, M. Yasuda, K. Mawatari, et al., "Analysis of Purine in Purine-Rich Cauliflower," Nucleosides, Nucleotides and Nucleic Acids, Vol. 29, No. 4-5, 2010, pp. 518-521. http://dx.doi.org/10.1080/15257771003741372

[10] L. F. Cavalieri, A. Bendich, J. F. Tinker and G. B. Brown, "Ultraviolet Absorption Spectra of Purines, Pyrimidines and Triazolopyrimidines," Journal of the American Chemical Society, Vol. 70, No. 11, 1948, pp. 3875-3880. http://dx.doi.org/10.1021/ja01191a102 